CLINICAL STUDY

\title{
Factors predicting relapse of nonfunctioning pituitary macroadenomas after neurosurgery: a study of 142 patients
}

\author{
Sophie Brochier ${ }^{1,6, *}$, Françoise Galland ${ }^{1, *}$, Michèle Kujas ${ }^{1}$, Fabrice Parker ${ }^{2}$, Stephan Gaillard ${ }^{3}$, \\ Christian Raftopoulos ${ }^{7}$, Jacques Young ${ }^{1,4,5}$, Orsalia Alexopoulou ${ }^{6}$, Dominique Maiter ${ }^{6}$ and Philippe Chanson ${ }^{1,4,5}$ \\ Assistance Publique-Hôpitaux de Paris, ${ }^{1}$ Hôpital de Bicêtre, Service d'Endocrinologie et des Maladies de la Reproduction, ${ }^{2}$ Service de Neurochirurgie, \\ Le Kremlin-Bicêtre F-94275, France, ${ }^{3}$ Hôpital Foch, Service de Neurochirurgie, Suresnes F-92151, France, ${ }^{4}$ Institut National de la Santé et de la \\ Recherche Médicale, Unité 693, Le Kremlin-Bicêtre F-94276, France, ${ }^{5}$ Univ Paris-Sud 11, Faculté de Médecine Paris-Sud, Unité Mixte de Recherche- \\ S693, Le Kremlin-Bicêtre F-94276, France, ${ }^{6}$ Service d'Endocrinologie et Nutrition, Cliniques Universitaires Saint-Luc, Université Catholique de Louvain, \\ 1200 Bruxelles, Belgique and ${ }^{7}$ Service de Neurochirurgie, Cliniques Universitaires Saint-Luc, Université Catholique de Louvain, 1200 Bruxelles, Belgique \\ (Correspondence should be addressed to P Chanson at Hôpital de Bicêtre, Service d'Endocrinologie et des Maladies de la Reproduction; \\ Email: philippe.chanson@bct.aphp.fr)
}

*(S Brochier and F Galland contributed equally to this work)

\begin{abstract}
Context: Adequate postoperative management of nonfunctioning pituitary macroadenomas (NFMAs) remains a challenge for the clinician.

Objective: To identify predictive factors of NFMA relapse after initial surgery.

Patients and methods: This retrospective study included 142 patients operated for an NFMA in two academic centers (CHU Bicêtre in France and UCL St Luc in Belgium). The rate of tumor relapse, defined as recurrence after total surgical resection or regrowth of a surgical remnant, as well as predictive factors was analyzed.

Results: During a mean follow-up of 6.9 years, 10 out of 42 patients (24\%) who had complete macroscopic resection of their tumor had recurrence, and 47 out of 100 patients (47\%) with a surgical remnant experienced regrowth. The overall relapse rates were 25,43 , and $61 \%$ at 5,10 , and 15 years respectively. Invasion of the cavernous sinus, absence of immediate radiotherapy after the first neurosurgery, and immunohistochemical features of the tumor (mainly positive immunostaining for several hormones or for hormones other than gonadotropins) were independent risk factors for tumor relapse. Incomplete excision was only associated with relapse when invasion was withdrawn from the analysis, suggesting that these two factors are closely linked.

Conclusion: NFMAs frequently recur/regrow after initial surgery, particularly when tumor is invasive, precluding complete removal. Immunohistochemical features such as positive immunostaining for several hormones or for hormones other than gonadotropins could help to predict undesirable outcomes.
\end{abstract}

European Journal of Endocrinology 163 193-200

\section{Introduction}

Nonfunctioning pituitary macroadenomas (NFMAs) are the most frequent pituitary macroadenomas (1-3), but their treatment and follow-up remains a difficult challenge. Patients often present with symptoms of mass effects, such as visual field defects, chronic headache, and hypopituitarism. Transsphenoidal surgery is considered as the treatment of choice, and significant tumor debulking improves visual field disorders in $80 \%$ of patients and relieves headaches in almost every case (4). However, even after complete or near complete surgical resection, NFMAs regrow in $12-58 \%$ of patients within 5 years (5-8), and medical therapy with dopamine agonists or somatostatin analogs has a variable and often limited impact on the risk of recurrence (9). Some centers consider immediate postoperative radiation therapy in an attempt to prevent tumor regrowth $(6,10-12)$, but this approach carries a risk of complications such as hypopituitarism (13), cerebrovascular disease $(14,15)$, potential neurocognitive dysfunction (16), and a low but welldocumented long-term risk of secondary intracranial tumors (17).

Recent studies have examined the natural history of pituitary NFMA remnants in surgically treated patients (5-8), but the number of patients studied and the length of postsurgical follow-up were often limited. As a result, it is still difficult to predict the individual risk of relapse (recurrence/regrowth) after neurosurgery. We retrospectively studied a very large number of NFMA patients with long-term follow-up after surgery in order to 
identify factors associated with tumor relapse and thereby determine which patients might benefit from postoperative adjuvant treatment or at least require closer follow-up.

\section{Patients and methods}

\section{Patient selection and study design}

All patients with a diagnosis of clinical NFMA (diameter $>10 \mathrm{~mm}$ on computed tomography (CT) scan or magnetic resonance imaging (MRI)) and who were seen in one of the two participating endocrine centers between 1975 and 2005 were initially included in this retrospective study $(n=177)$. Patients presenting with amenorrhea-galactorrhea or decreased libido were also considered, at least for the initial analysis, in order to avoid excluding NFMA with hyperprolactinemia related to pituitary stalk compression. Prolactinoma was considered unlikely if the prolactin (PRL) level was below $150 \mu \mathrm{g} / \mathrm{l}$, and this diagnosis was thereafter formally excluded by immunocytochemical studies. Among the 177 patients, 21 patients were not operated, and ten patients had a follow-up lasting $<6$ months. One hundred and forty-two patients who had both a surgical resection of their pituitary tumor and biochemical and imaging follow-up study for at least 6 months after surgery were finally included in this study. At baseline, all the patients had a complete hormonal evaluation as described (18), to verify if they had either hypersecretion or deficiency of PRL, ACTH, GH, TSH, FSH/LH, or free $\alpha$-subunit.

We collected anthropometric, clinical, and biochemical information recorded at diagnosis and regularly after surgery. Assessment of pituitary images was made by the neurosurgeon, a neuroradiologist and an endocrinologist who estimated the three-dimensional size of the tumor and looked for signs of cavernous sinus invasion. Information was also collected, about the type of initial surgery (transcranial, $n=9$; or transsphenoidal, $n=133$; no endoscopic neurosurgery) and number of operations. Data concerning medical therapy (somatostatin analogs, bromocriptine, and cabergoline) and radiotherapy were also collected.

A variety of radiotherapy techniques and beam energies were used, depending on the date of the procedure: 1.25-MV rays from a ${ }^{60}$ Co source with a three-field arrangement (left and right lateral and anterior portals) before 1985, and 15- to 23-MV X-ray beams produced by a linear accelerator after 1985 . Since 1994 , a conformal treatment planning procedure and a 15-MV X-ray beam were used. The target volume was defined on lateral and anterior simulation films guided by radiological and surgical findings, and, after 1994, with contrast-enhanced CT scans, in a treatment position guided by radiological findings. Five coplanar, eight and seven noncoplanar fixed-beam techniques were used successively to spare surrounding normal tissues. The dose was given at a rate of 1.8 Gy daily, 5 days a week.

After surgery, to establish whether pituitary disease was cured or persistent, clinical, hormonal, and radiological evaluations (CT scan before 1985 and MRI thereafter) were performed at 3 months. The diagnosis of 'complete surgical resection' was based on the absence of any visible residual tumor at imaging performed 3 months after surgery. Pituitary imaging was then performed at 6 and 12 months during the first year and yearly thereafter. Relapse was defined either as recurrence of an apparently completely resected pituitary tumor (no visible remnant at first postoperative imaging) or regrowth of a surgical remnant (more than $2-\mathrm{mm}$ increase in at least one diameter). Visual evaluation was performed 3, 6, and 12 months after surgery in patients who presented preoperative visual field disorders. This evaluation was pursued yearly in case of persistent visual field defects. Hormonal assessment was also performed yearly to detect pituitary deficiency.

\section{Hormonal measurements}

Hormonal measurements were performed using commercially available kits.

\section{Immunohistochemical analysis}

Pituitary specimens were fixed in Gerard's fluid until 1999 and in buffered formol (10\%) thereafter, before embedding in paraffin wax. Four-micrometer sections were prepared for histological and immunocytochemical studies. All immunocytochemical analyses (FSH, LH, $\alpha$-subunit, TSH, ACTH, GH, and PRL) and the final immunopathological classification of the NFMAs were done, as previously described (19-22), by the same pathologist (M K) who was blinded to the clinical data. Complete immunohistochemical analysis was possible in 130 cases. Positive immunostaining for $\mathrm{LH} \beta$ and/or FSH $\beta$ and/or $\alpha$-subunit was considered diagnostic of gonadotroph adenomas (subgroup 1). A diagnosis of null cell adenoma was made when immunostaining was negative for all studied hormones (subgroup 2). Plurihormonal adenoma was diagnosed when immunostaining was positive for two or more pituitary hormones and at least one hormone different from gonadotropins (subgroup 3). A diagnosis of silent ACTH, GH, or GH/PRL adenoma was made (subgroup 4) if immunostaining was positive for ACTH, GH, or GH/PRL (mammosomatotroph cells) and biochemical tests ruled out hypersecretion of these hormones.

\section{Statistical analysis}

Differences between subgroups were analyzed using Student's t-test for normally distributed continuous values and the Mann-Whitney test for non normally 
Table 1 General characteristics of the 142 patients with a nonfunctioning pituitary macroadenoma. Data are shown as means \pm s.D. (range) or as proportions of evaluable subjects (\%).

\begin{tabular}{ll}
\hline & All patients $(n=142)$ \\
\hline Mean age at diagnosis (years) & $53 \pm 14(23-86)$ \\
Sex ratio (M/F) & $84 / 58$ \\
Follow-up after surgery (years) & $6.9 \pm 5.1(0.5-30)$ \\
Maximal tumor height (mm) & $26.3 \pm 9.5$ \\
Cavernous sinus invasion & $64 / 119(54 \%)$ \\
Visual field deficits & $76 / 141(54 \%)$ \\
Pituitary hormone deficits (\%) & $18 / 23 / 17 / 17 / 24 / 1$ \\
$\quad(0 / 1 / 2 / 3 / 4 / 5$ deficits) & $133 / 9$ \\
Surgery: TSS/TC & $100 / 142(70 \%)$ \\
Postsurgical remnant & $15 / 142(11 \%)$ \\
Postsurgical radiation therapy & \\
\hline
\end{tabular}

TSS, transsphenoidal; TC, transcranial surgery.

distributed continuous values. The $\chi^{2}$ test was used for categorical variables. The tumor relapse-free survival probability was analyzed by a modified Kaplan-Meier approach, accounting for competing risks as informative censoring and described by Satagopan et al. (23). In our study, the only competing risk was death occurring before any relapse in three patients, after time intervals of 1.0, 4.2, and 17.5 years respectively. Survival curves were compared between subgroups of patients by nonparametric log-rank tests. A Cox multivariate regression analysis was used to assess the independent influence of specific factors on the tumor relapse rate and to define hazard ratios for each significant covariate. Two-sided $P$ values below 0.05 were considered statistically significant. The SPSS software version 18.0 (SPSS Inc., Chicago, IL, USA) was used for all statistical analyses.

\section{Results}

\section{Clinical, biological, and radiological findings}

The main characteristics of the patients are shown in Table 1. A total of 142 surgically treated patients were included, of whom 58 were women $(41 \%)$ and 27 were postmenopausal. Mean age at diagnosis was $53 \pm 14$ years (females, $49 \pm 15$ years; males, $56 \pm 13$ years, $P<0.01)$. The presenting symptoms were visual disorders in $44 \%$ of patients; decreased libido, sexual dysfunction, and/or amenorrhea/oligomenorrhea in $29 \%$ of patients; and headache in $25 \%$ of patients. The macroadenoma was an incidental finding in $21 \%$ of cases, and pituitary apoplexy was the first sign in $7 \%$ of patients. Objective defects were found by visual field examination in $53 \%$ of patients. Preoperative deficits in gonadotropins, TSH, and ACTH were present in 77, 47, and $40 \%$ of patients respectively. GH deficiency was diagnosed in $48 \%$ of patients but was not specifically sought in all patients. Twenty-four percent of the patients had panhypopituitarism, while pituitary function was considered normal in $18 \%$ of cases (Table 1). Only one patient had diabetes insipidus preoperatively, in the context of a severe pituitary apoplexy. No hypersecretion of ACTH, GH, or TSH was found, including subclinical forms.

Preoperative imaging studies displayed a mean tumor height of $26.3 \pm 9.5 \mathrm{~mm}$ (range 11-70 mm; median $25 \mathrm{~mm}$ ) (Table 1). One or both cavernous sinuses were invaded in $54 \%$ of the patients.

Surgery was performed by three skilled dedicated neurosurgeons in France and Belgium, using the transsphenoidal route in 133 patients $(94 \%)$ and the transcranial route in the remaining $9(6 \%)$ because of a large suprasellar extension. The operations were performed urgently in $12 \%$ of cases, owing to apoplexy or abrupt onset of loss of visual acuity or blindness. No significant differences were found between both centers in terms of patient and tumor's characteristics, surgical outcome, or relapse rate (data not shown).

Immediate postoperative radiotherapy was given after the first operation in 15 cases (Table 1) because of a significant remnant and/or a high risk of relapse, as judged by the physician (on the basis of young age at diagnosis, size of the remnant, markedly invasive tumor, or pathological examination of the adenoma tissue showing high proliferation index in a few cases). The total dose ranged between 45 (used in more than half of the patients) and $56 \mathrm{~Gy}$.

\section{Postoperative follow-up}

Follow-up ranged from 0.5 to 30 years (mean \pm s.D.: $6.9 \pm 5.1$; median: 5.5 years) (Table 1). It lasted more than 5 years in 79 cases $(56 \%)$ and more than 10 years in 37 cases $(26 \%)$. During the postoperative follow-up, visual field normalized in $29 \%$ of patients, while it improved in $48 \%$, remained stable in $17 \%$, and deteriorated in $5 \%$.

Hormonal evaluation at the end of the follow-up was available in 128 patients. Deficits in gonadotropins,

Table 2 General characteristics of the patients with and without tumor relapse after surgical removal of nonfunctioning pituitary macroadenoma.

\begin{tabular}{lll}
\hline & $\begin{array}{l}\text { Patients without } \\
\text { relapse }(n=85)\end{array}$ & $\begin{array}{l}\text { Patients with } \\
\text { relapse }(n=57)\end{array}$ \\
\hline $\begin{array}{ll}\text { Mean age at diagnosis (years) } \\
\text { Sex ratio (M/F) }\end{array}$ & $53.4 \pm 14.0$ & $52.6 \pm 14.5$ \\
$\begin{array}{l}\text { Follow-up after surgery } \\
\text { (years) }\end{array}$ & $7.9 \pm 5.8$ & $32 / 25$ \\
$\begin{array}{l}\text { Maximal tumor height (mm) } \\
\text { Cavernous sinus }\end{array}$ & $24.9 \pm 8.6$ & $5.4 \pm 3.5^{\star}$ \\
$\quad$ invasion & $34 / 78(44 \%)$ & $28.2 \pm 10.4$ \\
$\begin{array}{l}\text { Postsurgical remnant } \\
\text { Postsurgical radiation }\end{array}$ & $53 / 85(62 \%)$ & $48 / 52(69 \%)^{\star}$ \\
$\quad$ therapy & $14 / 85(16 \%)$ & $\left.1 / 57(2 \%)^{*}\right)^{\star}$ \\
\hline
\end{tabular}

${ }^{\star} P<0.01$ versus patients without relapse. 
TSH, and ACTH were present in 65,52 , and $46 \%$ of patients respectively; GH deficiency was diagnosed in $63 \%$ of patients. Thirty-six percent of the patients had panhypopituitarism, while pituitary function was considered normal in 25\% of cases. Compared with preoperative hormonal evaluation, gonadotropic function improved significantly $(P<0.01)$, while corticotropic and thyrotropic function remained unchanged; GH deficiency was more prevalent $(P<0.01)$ after surgery, as was diabetes insipidus $(7 \%, P<0.001)$.

\section{Immunohistochemical characteristics}

Subgroup 1 (gonadotroph adenomas) accounted for $64 \%(83 / 130)$ of the tumors, and subgroup 2 (null cell adenomas) accounted for $22 \%(29 / 130)$ of the tumors. Subgroup 3 (plurihormonal adenomas) represented 8\% (10/130) of the tumors, and showed positive immunostaining for LH $\beta$ and/or FSH $\beta$ and/or $\alpha$-subunit + TSH $\beta$ in six cases, LH $\beta$ and/or FSH $\beta$ and/or $\alpha$-subunit $+\mathrm{GH}$ in three cases, and LH $\beta+$ PRL in one case. Subgroup 4 (silent adenomas) accounted for $6 \%$ (8/130) of the tumors, which showed positive immunostaining for GH in two cases, ACTH in four cases, and GH/PRL in two cases.

\section{Tumor relapse rate and predictive factors}

Tumor relapse was observed in a total of $57 / 142$ patients $(40 \%)$ during a total follow-up period of 972 patient-years. These relapses were treated by a second neurosurgery in 14 cases $(24 \%)$, by radiotherapy alone in 17 cases $(30 \%)$, and by combined surgery and radiotherapy in 14 cases $(24 \%)$. The remaining 12 cases $(21 \%)$ are still under close surveillance. Compared with other patients, patients who relapsed had significantly shorter follow-up (ending, by definition, at diagnosis of relapse), more frequent cavernous sinus invasion, more frequent incomplete surgery, and they were less likely to have had immediate postsurgical radiotherapy (Table 2). The overall relapse rates were 25,44 , and $64 \%$ respectively at 5,10 , and 15 years (Fig. $1 \mathrm{~A}$ and Table 3).

Tumor relapse was significantly associated with the presence of a postsurgical tumor remnant: $10(24 \%)$ of 42 patients had a true recurrence after complete adenoma resection, and $47(47 \%)$ of 100 patients had a gradual increase in the size of a postoperative remnant. The calculated relapse rates at 5,10 , and 15 years were respectively 18,32 , and $34 \%$, and 30 , 48 , and $70 \%(P<0.025$; Fig. $1 \mathrm{~B})$. Cavernous sinus extension had also a negative influence on the risk of relapse. Indeed, $36(51 \%)$ of 70 patients with invasion had a relapse, compared with only $16(27 \%)$ of 60 patients without invasion $(P<0.01)$. The $5-, 10-$, and 15 -year relapse rates were also higher in patients with invasive tumors $(37,56$, and $70 \%$ respectively) than in
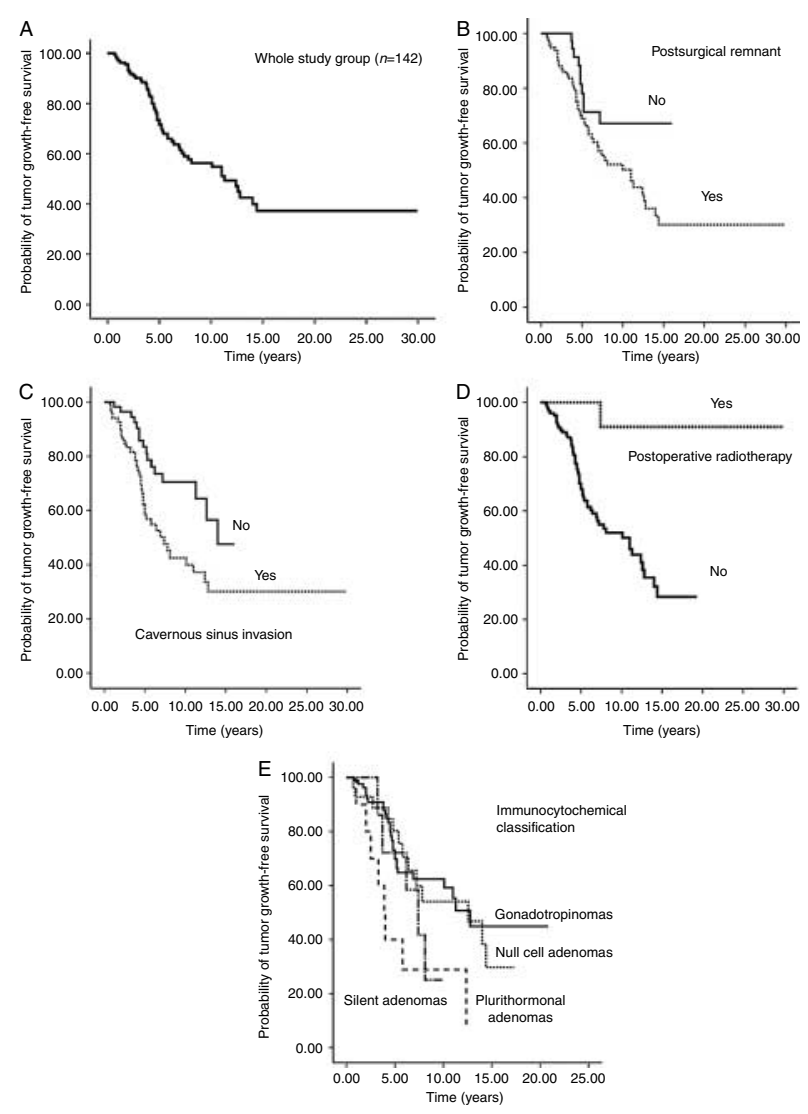

Figure 1 (A) Kaplan-Meier estimate of tumor growth-free survival probability in the whole study group $(n=142)$, after adjusting for death before relapse as competing risk event (see Patients and methods section). Calculated relapse rates at 5,10 , and 15 years were 25,43 , and $61 \%$ respectively. (B) Kaplan-Meier estimates of tumor growth-free survival probability according to the absence or the presence of a postsurgical remnant, after adjusting for death before relapse as competing risk event (see Patients and methods section). Calculated relapse rates at 5,10 , and 15 years were 18 , 32 , and $34 \%$, and 30,48 , and $70 \%$ in the groups without and with a postsurgical remnant respectively $(P<0.025)$. (C) Kaplan-Meier estimates of tumor growth-free survival probability according to the absence or the presence of a cavernous sinus invasion, after adjusting for death before relapse as competing risk event (see Patients and methods section). Calculated relapse rates at 5,10 , and 15 years were 16,29 , and $52 \%$, and 37,56 , and $70 \%$ in the groups without and with cavernous sinus invasion respectively $(P<0.01)$. (D) Kaplan-Meier estimates of tumor growth-free survival probability according to the absence or the presence of a postoperative radiotherapy, after adjusting for death before relapse as competing risk event (see Patients and methods section). Calculated relapse rates at 5,10 , and 15 years were 30,48 , and $72 \%$, and 0,9 , and $9 \%$ in the groups without and with postoperative radiotherapy respectively $(P<0.005)$. (E) Kaplan-Meier estimates of tumor growth-free survival probability according to immunocytochemical classification (1, null cell adenomas; 2 , gonadotropinomas; 3, plurihormonal adenomas; and 4, silent ACTH, GH, or $\mathrm{GH} / \mathrm{PRL}$ adenomas), after adjusting for death before relapse as competing risk event (see Patients and methods section).

Calculated 5-, 10-, and 15-year relapse rates were 20, 46, and $70 \%$ in subgroup $1 ; 27,38$, and $55 \%$ in subgroup $2 ; 60,71$, and $93 \%$ in subgroup 3; and 28 and $75 \%$ (not evaluable at 15 years) in subgroup $4(P<0.01)$. 
Table 3 Cox multivariate analysis of factors independently predicting relapse of nonfunctioning pituitary macroadenomas after initial surgery ${ }^{\mathrm{a}}$.

\begin{tabular}{lccc}
\hline Variable & Hazard ratio & $\mathbf{9 5 \%} \mathbf{C l}$ & $\boldsymbol{P}$ value \\
\hline Cavernous sinus invasion & 2.511 & $1.370-4.602$ & 0.003 \\
Immunocytochemistry & 1.514 & $1.043-2.199$ & 0.029 \\
Postoperative remnant & 1.435 & $0.661-3.114$ & 0.361 \\
Postoperative radiotherapy & 0.071 & $0.010-0.521$ & 0.009 \\
\hline
\end{tabular}

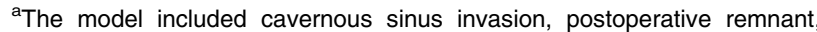
and postoperative radiotherapy as dichotomic variables, and the immunocytochemical classification in four strata.

patients with noninvasive tumors $(16,29$, and $52 \%$, $P<0.01$; Fig. 1C).

Only one $(6 \%)$ of the 15 subjects who received immediate postsurgical irradiation relapsed, compared with $56(44 \%)$ of the 127 patients who were not irradiated $(P=0.005)$; respective relapse rates at 5,10 , and 15 years were 0,9 , and 9 , and 30,48 , and $72 \%$ $(P<0.005$; Fig. 1D). Interestingly, the relapse rates differed significantly $(P=0.01)$ across patients with null cell adenomas $(13 / 29,45 \%)$, gonadotropinomas (28/83, 34\%), plurihormonal adenomas $(8 / 10,80 \%)$, and adenomas expressing hormones other than gonadotropins $(5 / 8,63 \%)$. Estimated 5- and 10-year relapse rates were respectively 20 and $46 \%, 27$ and $38 \%, 60$ and $71 \%$, and 28 and $75 \%$ (Fig. $1 \mathrm{E}, P<0.01$ ).

Other parameters such as age at initial surgery, gender, tumor height, a pre-operative PRL level above $25 \mu \mathrm{g} / \mathrm{l}$, and pre-operative medical treatment did not predict relapse, although age over 65 years and a pre-operative PRL level above $25 \mu \mathrm{g} / \mathrm{l}$ were close to significance $(P=0.06$ and 0.07 respectively). There was also no difference in relapse rates between patients operated by the transsphenoidal versus the transcranial route (10-year rates of 43 and $45 \%$ respectively), nor between patients operated before $(n=84)$ or after 1999 $(n=58)$, with estimated 10-year relapse rates of 42 and $45 \%$ respectively (NS).

In a Cox multivariate regression analysis, invasion of the cavernous sinus, the absence of immediate radiotherapy after initial neurosurgery, and immunopathological status were independent risk factors for tumor recurrence/regrowth (Table 3). The presence of a postoperative tumor remnant only had a significant influence when invasion was withdrawn from the analysis (Hazard ratio 2.1, P<0.05), suggesting that these two factors are closely associated. The influence of invasion and immunopathological status was still significant when irradiated patients were excluded from the analysis (data not shown).

\section{Discussion}

In this series of 142 surgically treated NFMA patients, with follow-up periods ranging from 0.5 to 30 years after surgery, the risk of tumor recurrence/regrowth was higher in case of cavernous sinus invasion, no immediate postoperative radiotherapy, positive immunostaining for hormones other than gonadotropins, and the presence of a postsurgical remnant.

The clinical characteristics of our patients are similar to those reported in other studies $(1,5,6,24-27)$. Presenting signs and symptoms were mainly related to mass effects of the tumor, namely visual field disorders, headache, and pituitary deficiencies (mainly gonadotropic). The macroadenoma was discovered incidentally in $21 \%$ of cases, a figure very similar to that reported by Dekkers et al. (27) but lower than that reported by Karavitaki et al. (37.5\%) (28). Unfortunately, no data on this mode of presentation were reported by Ferrante et al. (5), who analyzed the large Italian database of NFPAs. It must be underlined that cavernous sinus invasion was more frequent in our patients (54\%) than in previous series $(33-52 \%)(6,7,12,27)$. This might be related to underestimation of invasive status in patients who did not undergo surgery or who were studied with older, less precise imaging procedures (CT rather than MRI); explanation could be also related to the definition of the invasive status.

Table 4 Summary of the main results of recent studies on relapse after surgery of nonfunctioning pituitary macroadenomas.

\begin{tabular}{|c|c|c|c|c|c|c|}
\hline \multirow[b]{2}{*}{ Author, year (ref) } & \multirow{2}{*}{$\begin{array}{l}\text { Total no. of } \\
\text { patients }\end{array}$} & \multicolumn{2}{|c|}{$\begin{array}{l}\text { No. of relapses according to } \\
\text { the presence of a remnant }(\%)\end{array}$} & \multicolumn{2}{|c|}{$\begin{array}{l}\text { No. of relapses according to } \\
\text { postoperative RT }(\%)\end{array}$} & \multirow{2}{*}{$\begin{array}{c}\text { Mean (range) } \\
\text { follow-up (years) }\end{array}$} \\
\hline & & Remnant + & No remnant & $\mathrm{RT}+$ & No RT & \\
\hline Soto-Ares et al. (2002) (30) & 51 & $13 / 34(38 \%)$ & $0 / 17(0 \%)$ & - & $13 / 51(26 \%)$ & $5.6(2-12)$ \\
\hline Greenman et al. (2003) (6) & 122 & $41 / 78(53 \%)$ & $6 / 30(20 \%)$ & $5 / 14(35 \%)$ & $47 / 108(43 \%)$ & $4.2(1-11)$ \\
\hline Dekkers et al. (2006) (7) & 97 & $9 / 70(13 \%)$ & $1 / 27(4 \%)$ & $0 / 6(0 \%)$ & 11/91 (11\%) & $6.0(1-14)$ \\
\hline Ferrante et al. (2006) (5) & 226 & $59 / 153(39 \%)$ & 14/73 (19\%) & $14 / 76(18 \%)$ & $59 / 150(39 \%)$ & $5.7(2-28)$ \\
\hline Van den Bergh et al. (2007) (31) & 122 & 19/104 (18\%) & $1 / 18(6 \%)$ & $4 / 79(5 \%)$ & $17 / 43(40 \%)$ & $6.8(0.5-20)$ \\
\hline Losa et al (2008) (29) & 436 & $48 / 157(30 \%)$ & $36 / 279(13 \%)$ & $1 / 81(1 \%)$ & $216 / 355(61 \%)$ & $4.4(2-8)$ \\
\hline O’Sullivan et al. (2009) (8) & 126 & $53 / 100(53 \%)$ & $0 / 26(0 \%)$ & - & - & $5.7(1-25)$ \\
\hline Present study & 142 & $47 / 100(47 \%)$ & $10 / 42(24 \%)$ & $1 / 15(6 \%)$ & $56 / 127(44 \%)$ & $6.9(0.5-30)$ \\
\hline
\end{tabular}

$\mathrm{RT}$, radiotherapy.

${ }^{a}$ For this study, data were deduced from the reported 5- and 10-year recurrence rates. 
Postoperative remnants were present in $70 \%$ of our patients and were strongly associated with relapse, as reported elsewhere $(5-8,29-31)$. Complete resection of these NFMAs is often impossible, even for experienced surgeons. In previous studies, excision was reported to be incomplete in between 51 and $72 \%$ of cases $(5-7,30)$. Reported relapse rates vary from one study to another, and also depend on both the length of follow-up and the number of patients studied. An analysis of some of these studies shows that the absence of residual tumor after surgery and postoperative radiotherapy are invariably associated with lower risks of relapse (Table 4) $(5-8,30,31)$. Indeed, $32 \%$ of patients who had a postoperative tumor remnant experienced regrowth within $2.2-6.3$ years, whereas only $8 \%$ of patients with no tumor remnant experienced recurrence after 5.0-6.5 years. These figures are somewhat lower than in our study, most likely because follow-up was longer than in most previous studies. Interestingly, we found that incomplete surgery no longer had independent predictive value when sinus invasion was included in the analysis, suggesting that these two factors are closely related.

Cavernous sinus invasion was a strong independent predictive factor of recurrence/regrowth, as in previous studies $(6,32)$. However, invasive status is sometimes very difficult to determine, and dural biopsy during surgery is not routinely performed. In addition, microscopic dural invasion has been noted by some pathologists in the vast majority of macroadenoma patients with suprasellar extension (33), but its influence on the risk of relapse is uncertain (34).

An important new finding in our study is the influence of immunostaining characteristics on the risk of NFMA recurrence/regrowth, plurihormonal adenomas and silent ACTH or GH/PRL adenomas relapsing more frequently than gonadotropinomas and null cell adenomas. Plurihormonal immunostaining has previously been linked to more aggressive pituitary tumors. Indeed, silent subtype 3 tumors, which are plurihormonal, have been described as rare and aggressive (35). This subtype was first included in the WHO classification in 2004 (36-39), based on two major advances: first, better understanding of cell differentiation pathways and second, development of new specific MABs allowing more accurate classification (36). More aggressive behavior (including a higher relapse rate) has been reported for silent corticotroph adenomas $(40,41)$ but not for silent $\mathrm{GH}$ or GH/PRL adenomas.

We also confirm that immediate postoperative radiation therapy is independently associated with a much lower risk of recurrence/regrowth. Moreover, the relapse rate increased gradually during follow-up in patients who were not irradiated, reaching $72 \%$ after 15 years, whereas it plateaued at $9 \%$ after 10 years in irradiated patients. However, although radiotherapy is clearly effective in preventing recurrence/regrowth in this setting $(5-7,11,31,42,43)$ (Table 4), its place in the management of patients with pituitary tumors is controversial. Indeed, radiotherapy, at least when delivered with conventional modalities, carries a risk of hypopituitarism, secondary brain tumors, stroke, and possibly neurocognitive or neuropsychological impairment $(13,17,44)$. We observed no neurological adverse effects in this series, likely because conformational fractionated irradiation was used in the majority of cases. Park et al. (45) in a retrospective study of NFMA indicated that immediate postoperative radiotherapy may be eliminated for patients with complete or near complete resection of the adenoma who undergo longtime close follow-up. New techniques such as $\gamma$-knife radiosurgery may have fewer adverse effects (46) but their use in NFMA patients is often restricted by the large size of the remnants or their location very close to the optic tract.

One limitation of this study is the lack of data on the Ki67 proliferation factor expression (47). Unfortunately, owing to the nature of the fixation process used in the early years of this study, it was not possible to study this immunohistochemical marker in many of our tumor specimens. We are thus unable to either confirm or not the correlation between Ki67 immunostaining and the risk of recurrence, found in some studies $(48-50)$ but not in others (51-53).

In conclusion, in this large study of 142 operated nonfunctioning pituitary adenomas with a significant follow-up, we were able to demonstrate that the risk of relapse was significantly higher in patients with positive immunostaining for multiple hormones or hormones other than gonadotropins. The presence of cavernous sinus invasion and the absence of postoperative radiation therapy were also independent risk factors for tumor relapse. Our results show that radical surgical resection of NFMAs markedly lowers the risk of relapse. If surgery is incomplete, it remains to be confirmed whether radiotherapy should be performed immediately or can be postponed. Histological or molecular markers (54) for tumors at a very high risk of recurrence/ regrowth would help to avoid unnecessary irradiation. Finally, long-term surveillance is needed for all patients with these tumors.

\section{Declaration of interest}

The authors declare that there is no conflict of interest that could be perceived as prejudicing the impartiality of the research reported.

\section{Funding}

This research did not receive any specific grant from any funding agency in the public, commercial, or not-for-profit sector.

\section{Acknowledgements}

The authors thank Drs Michèle Bernier and Anne-Catherine Baglin and the technicians of the Service d'Anatomopathologie, Hôpital 
Foch, Suresnes, and Dr Catherine Lacroix of the Service d'Anatomopatholgie, Hôpital de Bicêtre, Le Kremlin-Bicêtre, for their help with immunocytochemistry.

This article is dedicated to André Visot, a neurosurgeon of Hôpital Foch, who operated on many of these patients and who recently passed away.

\section{References}

1 Chanson P \& Brochier S. Non-functioning pituitary adenomas. Journal of Endocrinological Investigation 200528 93-99.

2 Molitch ME. Nonfunctioning pituitary tumors and pituitary incidentalomas. Endocrinology and Metabolism Clinics of North America 200837 151-171, xi.

3 Greenman Y \& Stern N. Non-functioning pituitary adenomas. Best Practice and Research. Clinical Endocrinology and Metabolism 200923 625-638.

4 Mortini P, Barzaghi R, Losa M, Boari N \& Giovanelli M. Surgical treatment of giant pituitary adenomas: strategies and results in a series of 95 consecutive patients. Neurosurgery $2007 \mathbf{6 0}$ 993-1002 discussion 1003-1004.

5 Ferrante E, Ferraroni M, Castrignano T, Menicatti L, Anagni M, Reimondo G, Del Monte P, Bernasconi D, Loli P, Faustini-Fustini M, Borretta G, Terzolo M, Losa M, Morabito A, Spada A, BeckPeccoz P \& Lania AG. Non-functioning pituitary adenoma database: a useful resource to improve the clinical management of pituitary tumors. European Journal of Endocrinology 2006155 823-829.

6 Greenman Y, Ouaknine G, Veshchev I, Reider G II, Segev Y \& Stern N. Postoperative surveillance of clinically nonfunctioning pituitary macroadenomas: markers of tumour quiescence and regrowth. Clinical Endocrinology 200358 763-769.

7 Dekkers OM, Pereira AM, Roelfsema F, Voormolen JH, Neelis KJ, Schroijen MA, Smit JW \& Romijn JA. Observation alone after transsphenoidal surgery for nonfunctioning pituitary macroadenoma. Journal of Clinical Endocrinology and Metabolism 200691 1796-1801.

8 O'Sullivan EP, Woods C, Glynn N, Behan LA, Crowley R, O'Kelly P, Smith D, Thompson CJ \& Agha A. The natural history of surgically treated but radiotherapy-naive nonfunctioning pituitary adenomas. Clinical Endocrinology 200971 709-714.

9 Colao A, Di Somma C, Pivonello R, Faggiano A, Lombardi G \& Savastano S. Medical therapy for clinically non-functioning pituitary adenomas. Endocrine-Related Cancer 200815 905-915.

10 Woollons AC, Hunn MK, Rajapakse YR, Toomath R, Hamilton DA, Conaglen JV \& Balakrishnan V. Non-functioning pituitary adenomas: indications for postoperative radiotherapy. Clinical Endocrinology 200053 713-717.

11 Gittoes NJ. Radiotherapy for non-functioning pituitary tumors when and under what circumstances? Pituitary 20036 103-108.

12 Alameda C, Lucas T, Pineda E, Brito M, Uria JG, Magallon R, Estrada J \& Barcelo B. Experience in management of 51 non-functioning pituitary adenomas: indications for post-operative radiotherapy. Journal of Endocrinological Investigation 200528 18-22.

13 Fernandez A, Brada M, Zabuliene L, Karavitaki N \& Wass JA. Radiation-induced hypopituitarism. Endocrine-Related Cancer 200916 733-772.

14 Brada M, Ashley S, Ford D, Traish D, Burchell L \& Rajan B. Cerebrovascular mortality in patients with pituitary adenoma. Clinical Endocrinology 200257 713-717.

15 Erfurth EM, Bulow B, Svahn-Tapper G, Norrving B, Odh K, Mikoczy Z, Bjork J \& Hagmar L. Risk factors for cerebrovascular deaths in patients operated and irradiated for pituitary tumors. Journal of Clinical Endocrinology and Metabolism 200287 4892-4899.

16 Hahn CA, Zhou SM, Raynor R, Tisch A, Light K, Shafman T, Wong T, Kirkpatrick J, Turkington T, Hollis D \& Marks LB. Dose-dependent effects of radiation therapy on cerebral blood flow, metabolism, and neurocognitive dysfunction. International Journal of Radiation Oncology, Biology, Physics 200973 1082-1087.
17 Minniti G, Traish D, Ashley S, Gonsalves A \& Brada M. Risk of second brain tumor after conservative surgery and radiotherapy for pituitary adenoma: update after an additional 10 years. Journal of Clinical Endocrinology and Metabolism 200590 800-804.

18 Chanson P. Pituitary tumors: overview of therapeutic options. In Principles and Practice of Endocrinology $\mathcal{E}$ Metabolism, edn 3 , pp 182-194. Ed KL Becker. Philadelphia: Lippincott Williams \& Wilkins, 2000.

19 Chanson P, Pantel J, Young J, Couzinet B, Bidart JM \& Schaison G. Free luteinizing-hormone beta-subunit in normal subjects and patients with pituitary adenomas. Journal of Clinical Endocrinology and Metabolism 199782 1397-1402.

20 Polak M, Bertherat J, Li JY, Kujas M, Le Dafniet M, Weizani H, Van Effenterre R, Epelbaum J \& Turpin G. A human TSH-secreting adenoma: endocrine, biochemical and morphological studies. Evidence of somatostatin receptors by using quantitative autoradiography. Clinical and biological improvement by SMS 201-995 treatment. Acta Endocrinologica 1991124 479-486.

21 Couzinet B, Young J, Kujas M, Meduri G, Brailly S, Thomas JL, Chanson P \& Schaison G. The antigonadotropic activity of a 19-nor-progesterone derivative is exerted both at the hypothalamic and pituitary levels in women. Journal of Clinical Endocrinology and Metabolism 199984 4191-4196.

22 Chanson P, Daujat F, Young J, Bellucci A, Kujas M, Doyon D \& Schaison G. Normal pituitary hypertrophy as a frequent cause of pituitary incidentaloma: a follow-up study. Journal of Clinical Endocrinology and Metabolism 200186 3009-3015.

23 Satagopan JM, Ben-Porat L, Berwick M, Robson M, Kutler D \& Auerbach AD. A note on competing risks in survival data analysis. British Journal of Cancer 200491 1229-1235.

24 Dekkers OM, van der Klaauw AA, Pereira AM, Biermasz NR, Honkoop PJ, Roelfsema F, Smit JW \& Romijn JA. Quality of life is decreased after treatment for nonfunctioning pituitary macroadenoma. Journal of Clinical Endocrinology and Metabolism 200691 3364-3369.

25 Snyder PJ. Gonadotroph cell adenomas of the pituitary. Endocrine Reviews $19856552-563$.

26 Snyder PJ. Clinically nonfunctioning pituitary adenomas. Endocrinology and Metabolism Clinics of North America 199322 163-175.

27 Dekkers OM, Hammer S, de Keizer RJW, Roelfsema F, Schutte PJ, Smit JWA, Romijn JA \& Pereira AM. The natural course of non-functioning pituitary macroadenomas. European Journal of Endocrinology $2007 \mathbf{1 5 6} 217-224$.

28 Karavitaki N, Collison K, Halliday J, Byrne JV, Price P, Cudlip S \& Wass JA. What is the natural history of nonoperated nonfunctioning pituitary adenomas? Clinical Endocrinology 200767 938-943.

29 Losa M, Mortini P, Barzaghi R, Ribotto P, Terreni MR, Marzoli SB, Pieralli S \& Giovanelli M. Early results of surgery in patients with nonfunctioning pituitary adenoma and analysis of the risk of tumor recurrence. Journal of Neurosurgery 2008108 525-532.

30 Soto-Ares G, Cortet-Rudelli C, Assaker R, Boulinguez A, Dubest C, Dewailly D \& Pruvo JP. MRI protocol technique in the optimal therapeutic strategy of non-functioning pituitary adenomas. European Journal of Endocrinology 2002146 179-186.

31 van den Bergh AC, van den Berg G, Schoorl MA, Sluiter WJ, van der Vliet AM, Hoving EW, Szabo BG, Langendijk JA, Wolffenbuttel BH \& Dullaart RP. Immediate postoperative radiotherapy in residual nonfunctioning pituitary adenoma: beneficial effect on local control without additional negative impact on pituitary function and life expectancy. International Journal of Radiation Oncology, Biology, Physics 200767 863-869.

32 Chang EF, Zada G, Kim S, Lamborn KR, Quinones-Hinojosa A, Tyrrell JB, Wilson CB \& Kunwar S. Long-term recurrence and mortality after surgery and adjuvant radiotherapy for nonfunctional pituitary adenomas. Journal of Neurosurgery $2008 \mathbf{1 0 8}$ 736-745.

33 Selman WR, Laws ER Jr, Scheithauer BW \& Carpenter SM. The occurrence of dural invasion in pituitary adenomas. Journal of Neurosurgery $1986 \mathbf{6 4} 402-407$. 
34 Meij BP, Lopes MB, Ellegala DB, Alden TD \& Laws ER Jr. The longterm significance of microscopic dural invasion in 354 patients with pituitary adenomas treated with transsphenoidal surgery. Journal of Neurosurgery 200296 195-208.

35 Erickson D, Scheithauer B, Atkinson J, Horvath E, Kovacs K, Lloyd RV \& Young WF Jr. Silent subtype 3 pituitary adenoma: a clinicopathologic analysis of the Mayo Clinic experience. Clinical Endocrinology 200971 92-99.

36 Al-Shraim M \& Asa SL. The 2004 World Health Organization classification of pituitary tumors: what is new? Acta Neuropathologica 2006111 1-7.

37 Asa S. Practical pituitary pathology: what does the pathologist need to know? Archives of Pathology E Laboratory Medicine 2008 132 1231-1240.

38 Farrell WE. The WHO typing of pituitary tumors: a commentary. Acta Neuropathologica 2006111 60-61.

39 Horvath A \& Stratakis CA. Clinical and molecular genetics of acromegaly: MEN1, Carney complex, McCune-Albright syndrome, familial acromegaly and genetic defects in sporadic tumors. Reviews in Endocrine \& Metabolic Disorders 20089 1-11.

40 Scheithauer BW, Jaap AJ, Horvath E, Kovacs K, Lloyd RV, Meyer FB, Laws ER Jr \& Young WF Jr. Clinically silent corticotroph tumors of the pituitary gland. Neurosurgery $2000 \mathbf{4 7} 723-729$ discussion 729-730.

41 Webb KM, Laurent JJ, Okonkwo DO, Lopes MB, Vance ML \& Laws ER Jr. Clinical characteristics of silent corticotrophic adenomas and creation of an internet-accessible database to facilitate their multi-institutional study. Neurosurgery $2003 \mathbf{5 3}$ 1076-1084 discussion 1084-1085.

42 Turner HE, Stratton IM, Byrne JV, Adams CB \& Wass JA. Audit of selected patients with nonfunctioning pituitary adenomas treated without irradiation - a follow-up study. Clinical Endocrinology $199951281-284$.

43 Gittoes NJL, Bates AS, Tse W, Bullivan B, Sheppard MC, Clayton RN \& Stewart PM. Radiotherapy for non-functioning pituitary tumours. Clinical Endocrinology $1998 \mathbf{4 8} 331-337$.

44 Littley MD, Shalet SM, Beardwell CG, Ahmed SR, Applegate G \& Sutton ML. Hypopituitarism following external radiotherapy for pituitary tumours in adults. Quarterly Journal of Medicine 1989 262 145-160.

45 Park P, Chandler WF, Barkan AL, Orrego JJ, Cowan JA, Griffith KA $\&$ Tsien $\mathrm{C}$. The role of radiation therapy after surgical resection of nonfunctional pituitary macroadenomas. Neurosurgery 200455 100-106 discussion 106-107.
46 Sheehan JP, Kondziolka D, Flickinger J \& Lunsford LD. Radiosurgery for residual or recurrent nonfunctioning pituitary adenoma. Journal of Neurosurgery 200297 408-414.

47 Salehi F, Agur A, Scheithauer BW, Kovacs K, Lloyd RV \& Cusimano M. Ki-67 in pituitary neoplasms: a review - part I. Neurosurgery $200965429-437$ discussion 437.

48 Paek KI, Kim SH, Song SH, Choi SW, Koh HS, Youm JY \& Kim Y. Clinical significance of Ki-67 labeling index in pituitary macroadenoma. Journal of Korean Medical Science 200520 489-494.

49 Jaffrain-Rea ML, Di Stefano D, Minniti G, Esposito V, Bultrini A, Ferretti E, Santoro A, Faticanti Scucchi L, Gulino A \& Cantore G. A critical reappraisal of MIB-1 labelling index significance in a large series of pituitary tumours: secreting versus non-secreting adenomas. Endocrine-Related Cancer 2002 9 103-113.

50 Filippella M, Galland F, Kujas M, Young J, Faggiano A, Lombardi G, Colao A, Meduri G \& Chanson P. Pituitary tumour transforming gene (PTTG) expression correlates with the proliferative activity and recurrence status of pituitary adenomas: a clinical and immunohistochemical study. Clinical Endocrinology $2006 \mathbf{6 5}$ 536-543.

51 Dubois S, Guyetant S, Menei P, Rodien P, Illouz F, Vielle B \& Rohmer V. Relevance of Ki-67 and prognostic factors for recurrence/progression of gonadotropic adenomas after first surgery. European Journal of Endocrinology 2007157 141-147.

52 Scheithauer BW, Gaffey TA, Lloyd RV, Sebo TJ, Kovacs KT, Horvath E, Yapicier O, Young WF Jr, Meyer FB, Kuroki T, Riehle DL \& Laws ER Jr. Pathobiology of pituitary adenomas and carcinomas. Neurosurgery 200659 341-353 discussion 341-353.

53 Turner HE, Nagy Z, Gatter KC, Esiri MM, Wass JA \& Harris AL Proliferation, bcl-2 expression and angiogenesis in pituitary adenomas: relationship to tumour behaviour. British Journal of Cancer 200082 1441-1445.

54 Galland F, Lacroix L, Saulnier P, Dessen P, Meduri G, Bernier M, Gaillard S, Guibourdenche J, Fournier T, Evain-Brion D, Bidart J-M \& Chanson P. Differential gene expression profiles of invasive and non-invasive non-functioning pituitary adenomas based on microarray analysis. Endocrine-Related Cancer 201017 361-371.

Received 2 May 2010

Accepted 11 May 2010 